\title{
Inclining Block Tariffs for Urban Water
}

\section{Lin Crase, Sue O'Keefe and J ennifer Burston}

U rban water pricing and the water-using behaviour of households continues to attract the attention of policy makers and scholars. Arguably, the strong focus on urban water belies the fact that almost three quarters of consumptive water use in Australia occurs in agricultural settings (ABS, 2004). Nevertheless, the political import of urban water prices, accompanied by concerns about anthropogenic climate change, rapidly diminishing water supplies and a vigorous reform agenda have made for a volatile policy-making environment. Against this background there is potential for agencies and regulators to become distracted from their primary responsibilities and allow emotional arguments to hold sway over rationality.

To date, one of the less contentious issues has been the widespread implementation of inclining block tariffs (IBTs) and their acceptance as an appropriate charging methodology. An IBT embodies an increase in the volumetric or per unit charge once a predetermined threshold of consumption is exceeded. Put simply, the first 'block' of water is sold at a low rate and as consumption moves into higher blocks the marginal water usage charge increases.

Boland and Whittington (2000) have argued that there are three main tasks to be accomplished in designing an IBT: deciding the number of blocks in the structure; assigning a volume of water to each block (that is, $\mathrm{X} \mathrm{kl}$ in Figure 1); and establishing a price to be charged for each of the blocks (that is, $\$ y$ and $\$ z$ in Figure 1). Rogers, de Silva and Bhatia (2002:7) contend that the first of these is essentially a management decision, while the second and third are 'political and social decisions'. In the light of the grounds used by the Victorian Essential Services Commission (ESC) to reject the introduction of some IBTs (see below), this raises serious questions about the role of economic regulation in this context. It also highlights other concerns about the economic merits of IBTs (see, for instance, Wittington, 2003; Sibly, 2006) and points to the need for closer scrutiny of their efficacy. Two pertinent questions arise: First, what are the features of an IBT that would lead an economic regulator to make decisions which are ostensibly in the political and social domains? Second, what types of information would be required to enhance decisions about the structure of IBTs, and is it feasible for this information to address the efficiency limitations embedded in IBTs?

In this paper we attempt to shed light on these questions by exploring the economic merits and limitations of IBTs. The paper specifically considers the notion of 'discretionary water use' and provides insights into its measurement dynamics in the context of rural and regional Victoria.

The paper is organised into six main parts. The following section briefly summarises the relative economic merits of IBTs. The next section addresses the

Lin Crase and Sue O'Keefe are respectively Associate Professor and Lecturer in the School of Business, La Trobe University, and Jennifer Burston is a Lecturer in the Department of Environmental Management, La Trobe University. 
notion of 'discretionary water use' and proposes a method for enumerating this thorny concept in different settings. An overview of empirical data collected from a survey of households in North East Victoria is then provided. The survey sought to identify the water volumes at which a two-step IBT might 'target' discretionary water use. Alternative approaches to interpreting these data and an assessment of the implications for different consumers are provided in the penultimate section. The final section examines the merits of attempting to describe 'discretionary water use', before offering some brief concluding remarks.

\section{The Deployment, Merits and Limitations of IBTs}

A diagrammatic representation of an IBT comprising two tariff blocks appears in Figure 1.

\section{Figure 1: A Two-Part (Step) IBT}

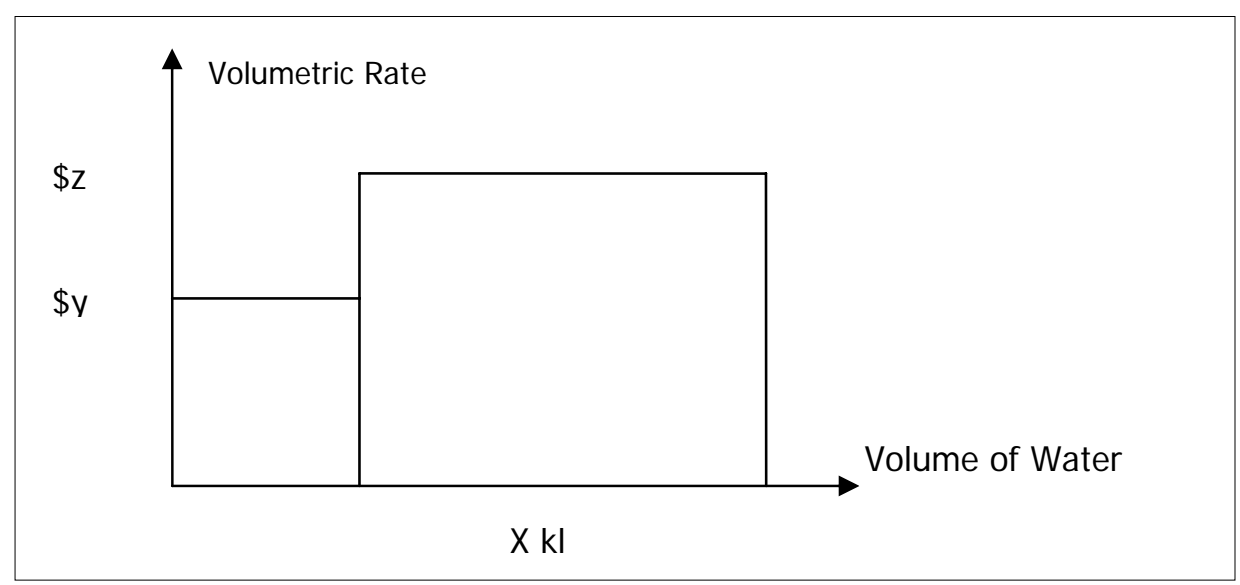

IBTs are currently applied in all major Australian cities except Newcastle, the Gold Coast and Darwin. The structure of IBTs used varies markedly. For instance, residents of Sydney and Adelaide face a two-block tariff (similar to that depicted in Figure 1), there are three blocks applied in Melbourne and Brisbane while five apply in Perth. The prices applied to each block also differ considerably, with block one charges being much higher in Sydney, Brisbane and Melbourne than in Perth, Adelaide and Canberra (Edwards, 2007).

In addition to variations between states there are significant discrepancies within jurisdictions. For example, in Victoria all metropolitan water utilities apply IBTs while many regional water authorities do not. Interestingly, the economic regulator in Victoria, the ESC, chose to reject the application of some regional water authorities to introduce IBTs on the basis that the proposed structures did not adequately target the discretionary component of household water use (ESC, 2005). In essence, the ESC argued that the threshold of the first tariff block ( X kl in Figure 1) was too high, although no alterative method of establishing an efficient threshold was provided.

Setting prices, particularly for water is rarely a simple task. Conventional economic wisdom suggests that prices need only be equated with marginal cost to 
generate efficiency. However, urban water pricing is confounded by several factors. First, water and wastewater services are generally regarded as natural monopolies and governments have long taken seriously their role to influence and regulate the behaviour of utilities of this kind. Second, there are political and environmental dimensions to the price of water and wastewater services that do not attend other monopoly suppliers. Claims of improved public health and sanitation, for instance, can impact on the 'acceptable' price for water. Third, there are philosophical objections expressed by some about charging a price for 'water for life'. This often gives rise to concerns about the equity of water pricing, although this is seldom defined with precision. Fourth, the technical operation of water utilities also complicates price setting because recouping only short-run marginal cost can potentially threaten the financial viability of the utility.

To better understand the merits of a water tariff structure it is important to acknowledge the objectives that underlie its design. Following Whittington (2003) and Boland and Whittington (2000) several fundamental objectives may be identified. First, a tariff needs to generate sufficient revenue to recover costs. These include the operation and maintenance costs, but the revenue stream must also be adequate to attract equity and debt financing. Revenue stability is another dimension of the revenue sufficiency objective although revenue stability per se cannot be justified on economic grounds alone. Second, tariffs need to be economically efficient - 'prices should signal to consumers the financial and other costs that their decisions to use water impose on the rest of society' (Whittington, 2003:63). Third, a tariff structure seeks to be equitable. Equity implies that 'similar customers are treated equally, and customers in different situations are not treated the same' (Whittington, 2003:63). Finally, a poverty alleviation objective is often assigned to water tariffs on the basis that water services are a fundamental right and the poor should at least have a minimum quantity of 'water for life'. The corollary of this argument is that water tariffs should also be used to curb excessive, wasteful or profligate water use. Unfortunately, the distinction between 'wasteful' water use and 'water for life' is contested.

The extent to which IBTs are able to deliver on each of these objectives is questionable. Cost recovery can be achieved with other pricing structures, such as a single volumetric charge set at long-run marginal cost. Clearly, this would expose the water utility to greater revenue fluctuations, although this is not strictly an economic consideration and can be accommodated by the imposition of access charges. In addition to providing revenue stability, access charges assist in the recovery of sunk costs but their relative size and basis are problematic. Currently, Victorian water authorities set a standard access charge for all properties connected to the water network, although Dwyer (2006:5) observes that a more efficient approach entails recovering the fixed component on the basis of land values (as is applied for wastewater services in South Australia. A variant of this technique is being progressively phased out in Western Australia).

IBTs fail on the economic efficiency front for several reasons. Setting multiple prices is inconsistent with the notion that customers should face the incremental costs of their actions, unless the service provided is attended by different costs. In essence, it is difficult to see how the cost of supplying a small number of households who use a larger quantity of water is higher than supplying 
small quantities of water to more numerous households. And yet an IBT gives rise to prices that suggest this is the case. The scale economies of tariff collection and the dynamics of water delivery would inter alia suggest that larger water users should face lower costs rather than higher costs. In addition, there are potential scale economies that attend consumption; larger households may frequently use less water per capita than smaller households (Dwyer, 2006:11).

The equity objectives of water tariffs are also not well served by IBTs. Recall that equity in this case means treating customers in similar circumstances equally and those in different circumstances differently. If 'the circumstances' in question are financial, there is no guarantee that water usage will be perfectly correlated with income. While there is some evidence of higher water use in richer households (see, for instance, DHS, 2004), many violations of this objective are also likely to arise from the imposition of IBTs. A high income apartment dweller could easily face much lower marginal tariffs than a large, low income household.

Finally, the notion that IBTs are consistent with the 'water for life' hypothesis would only hold if the first block was priced at below cost, or even assigned a zero price. It is worth considering the rationale that would support a free 'water for life' component embedded within water tariffs. Interestingly, food is equally necessary for sustenance and fundamental well-being (Edwards, 2007), but there is no call upon sandwich vendors or supermarkets to provide a minimum quantity of their produce to sustain all human life. This does not occur because it would seriously distort the incentives offered to food producers and be tantamount to taxing all food consumption above subsistence. Rather than taxing food alone, governments have found more effective means of providing subsistence to the poor; food stamps being a case in point. A similar argument could be mounted in favour of demogrants or water credits based on the number of residents in a household in preference to an IBT where the price of the first block would have to be set well below cost to achieve its purported poverty-alleviation objective.

\section{Using Consumer Data to Define Discretionary Water Use}

A related and practical challenge is distinguishing that component of water consumption which is genuinely discretionary. If IBTs are truly designed to target discretionary water use, which can be willingly curtailed in response to the higher price signal, it would be necessary to establish the step in the IBT at a level which reflects the bifurcation between discretionary and non-discretionary activities.

Basic water needs in developing countries have been estimated to lie in the range of 25-30 litres per capita per day (WHO, 1997; UN, 1993). This equates to about 9-11 kilolitres per annum or around 50 kilolitres for a 5 person household. If we accept that the genuine basic subsistence needs are universal, this stands in stark contrast to the various steps in IBTs applied in Australia's cities. For instance, in Canberra the first block expires at 100 kilolitres per annum while in Melbourne consumption up to 440 kilolitres per year is considered 'nondiscretionary'. In Sydney 400 kilolitres comprises the first block of the IBT while the threshold in Perth occurs at 150 kilolitres. Not only are these volumes grossly in excess of the reported volumes of water that would constitute truly nondiscretionary water consumption, their variation reflects the arbitrary manner in which this term has been interpreted by different economic regulators. 
Notwithstanding the shaky theoretical foundation of IBTs, they remain the tariff structure of choice amongst most water utilities and regulators in Australia. However, as we have noted, they are plagued by practical complexities which have not been consistently handled or resolved. One of the major challenges has been identifying a meaningful metric for discretionary water use which might be acceptable to water consumers. For instance, it might be argued that variations in the threshold level that applies to the first step in an IBT reflect geographical differences and the amounts of water required to deliver an equivalent quality of life in those settings. A household in an arid city might require more 'nondiscretionary' water than one located in a more temperate region. In reality, the differences in climate between Australian cities are not so great as to provide a satisfactory explanation for the variations in tariff structures that have emerged.

The arbitrary assignment of the volume in the first step in an IBT (that is, $X$ $\mathrm{kl}$ in Figure 1 ) is a non-trivial matter. Set too high, it would seriously erode claims by proponents of IBTs that the tariff structure signals the necessity for 'wise' use of water. Set too low, it would considerably punish non-discretionary water use. Moreover, given the overarching role of economic regulators to ensure that water utilities do not extract excessive rents from their customers, an inappropriate threshold volume can result in utilities enjoying excess profits (or losses).

A possible way to avoid arbitrary assignment of threshold volumes is to use consumer data about the distinction between discretionary and non-discretionary water-using activities. This might address some of the efficiency losses arising from an inappropriately defined threshold. By providing consumers the opportunity to identify those water-consuming tasks that they would be willing or able to curtail, and then distinguishing these activities from those conceived to be essential, it becomes feasible to set threshold limits that might at least approximate the preferences of consumers, rather than those of the regulator.

\section{An Empirical I nvestigation of Discretionary Water Use}

Given the practical difficulties of identifying the distinction between 'discretionary' and 'non-discretionary' water-use by employing secondary data, a survey of water users was conducted to gain insights into their preferences in this setting. The survey was conducted in North East Victoria, in the region where the ESC had formerly rejected the introduction of IBTs on the grounds that the water utility had not appropriately targeted 'non-discretionary' water use. The survey was accompanied by additional data gathering activities dealing with the consumers' preferences for tariff structures and feedback on other urban water policies.

Preceding the survey, a series of focus interviews and focus groups were conducted in both small and large towns across the region. Participants covered a range of ages and interests and were selected from different employment and social groups in the area. There is some climatic variability across the region and an effort was made to sample from residents in the different climate zones. Initially, the focus interviews used an open-ended format which endeavoured to elicit participants' description of their water-using habits, followed by a discussion centring on how much knowledge they had of each activity. The focus groups were then used to encourage participants to generate a ranking system by which water use activities could be categorised. These sessions revealed the difficulty of 
employing a simple bifurcation between 'discretionary' and 'non-discretionary' water-using activities. Most participants argued that there were many activities which should be permissible but the user should be constrained in some way. In addition, many participants indicated that they knew relatively little of the volumes of water that were associated with different household tasks and they felt this would have a bearing on their decisions. By and large there was consensus that outdoor activities contributed significantly to water consumption.

Information gathered from focus groups was used to design a survey instrument listing a range of household activities and asking respondents to categorise each into one of three groups, namely, activities that should not be restricted; actions that should be permissible with some restrictions on use; and behaviour that should be highly restricted or banned. Importantly, the second category listed examples of constraints that might be applied. More specifically, these were described as activities for which households should pay more for the privilege of undertaking them. The description of each of these categories was tested and refined with a pilot survey of 30 households. The list of activities presented to respondents was a composite of household tasks taken from various sources and web-based water-use calculators (for example, WSAA; South East Water; City of Melbourne). It included kitchen uses (like sinks and dishwashers), laundry appliances (water-efficient and less water-efficient washing machines), different types of showers and toilets and a range of outdoor activities.

An information booklet was designed and included with the survey instrument. The information booklet listed the typical water consumption that applied to each activity. This was calculated on a quarterly basis, with the exception of garden watering, lawn watering and topping up swimming pools, which was calculated seasonally. To make the task manageable, each activity was constrained by assumptions. For instance, the volume of water associated with AAA shower roses was limited to a household of 3 people who showered once per day for 5 minutes. The purpose of these descriptions was to give respondents some broad understanding of the water usage that related to each activity so that they would have some basis upon which to consider their merits.

The survey was distributed to a stratified sample of customers of the North East Regional Water Authority. The sample was stratified insofar as customers of the authority faced two different billing systems (for wastewater services) and the sample represented the roughly even split of customers across different tariffs. In September/October 2006, a total of 800 mail surveys were distributed to customers on one tariff structure while 886 surveys were sent to the other stratum. A reminder and thank you letter were sent 10 days after the initial mail out. The total response rate after two weeks was 20.05 per cent, with the split between the two sub samples roughly equal ( 52 per cent and 48 per cent). A summary of the characteristics of the 'average' respondent appears in Table 1.

Table 1: Characteristics of Average Survey Respondent

\begin{tabular}{|c|c|c|c|c|}
\hline Age (years) & $\begin{array}{c}\text { No. people in } \\
\text { household }\end{array}$ & $\begin{array}{c}\text { Household } \\
\text { income }\end{array}$ & $\begin{array}{c}\text { Estimate of last } \\
\text { water bill }\end{array}$ & $\begin{array}{c}\text { Rating of knowledge } \\
\text { about water use (0-7) }\end{array}$ \\
\hline 48.4 & 2.4 & $\$ 46052.29$ & $\$ 98.75$ & 4.5 \\
\hline
\end{tabular}




\section{Ascertaining the Volumetric Step of an I BT with Consumer I nput}

Initially, respondents were provided with a simple explanation of IBTs and asked a dichotomous choice question as to whether they would be in favour of their introduction. About 79 per cent of respondents supported the use of IBTs when they were described as 'supplying a reasonable amount of water at a lower rate but charging a higher rate once this level of consumption was exceeded'. No effort was made to define 'reasonable amount' at this point of the survey. Scrutiny of these data showed no significant relationship between support (or otherwise) for an IBT and age, household size, household income, the size of the last water bill or the consumer's ranking of their knowledge. However, those in support of an IBT were more inclined to rate a larger number of water using activities as 'discretionary' compared to those opposed to the introduction of IBTs.

The task of classifying each water-using activity followed this initial question about IBTs. Activities could be classified into one of three groups (unrestricted, permissible at a price and heavily restricted) and count data for each of the activities has been assembled. Perhaps not surprisingly, the distribution largely reflected the water by-laws and water restrictions that have been in place throughout much of Victoria for some time. For instance, many fundamental indoor uses were skewed towards category one (unrestricted use) while outdoor activities broadly fell into the second and third categories (permissible with price penalties or banned). Similarly, some outdoor activities were seen as more discretionary than others; watering lawns was more skewed towards the 'heavily restricted' category than garden watering. A sample of the count data is provided in Figure 2 to illustrate the distribution of some activities.

Figure 2: Sample Count Data of Ranking of Water-use Activities

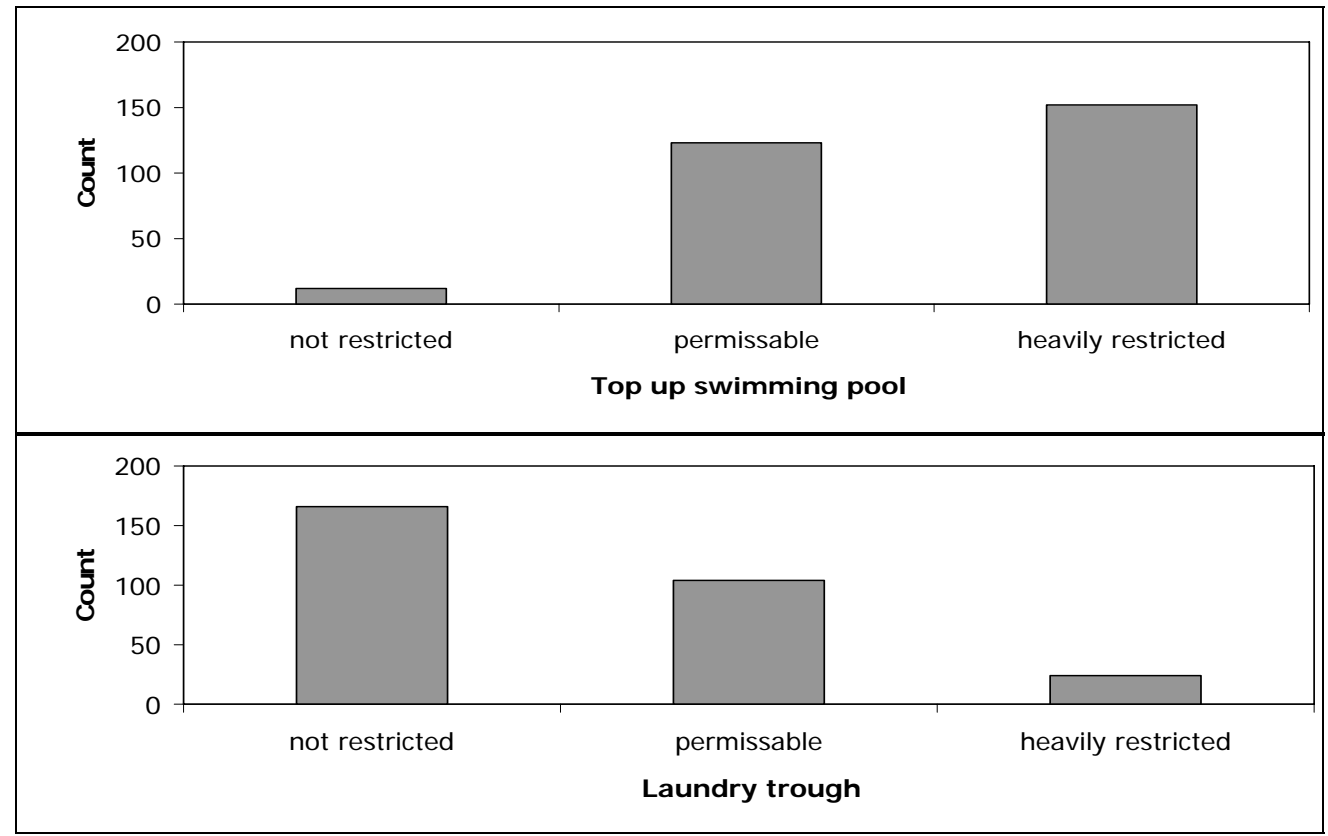


One way of categorising this information is to transform the data into universal measures of 'discretionary' versus 'non-discretionary' water use. For instance, by assigning each category a value $(1=$ not restricted; $2=$ permissible but facing some constraints (that is, a higher price); $3=$ heavily restricted) it then becomes feasible to adjudge the various water-using activities along the 'discretionary' continuum. For simplicity this has been undertaken initially using mean values and a 95 per cent confidence interval which appear in Figure 3, while a ranking of the mean score of each activity appears in Figure 4.

\section{Figure 3: Mean Values and 95 per cent Confidence Interval for Water-using Activities}

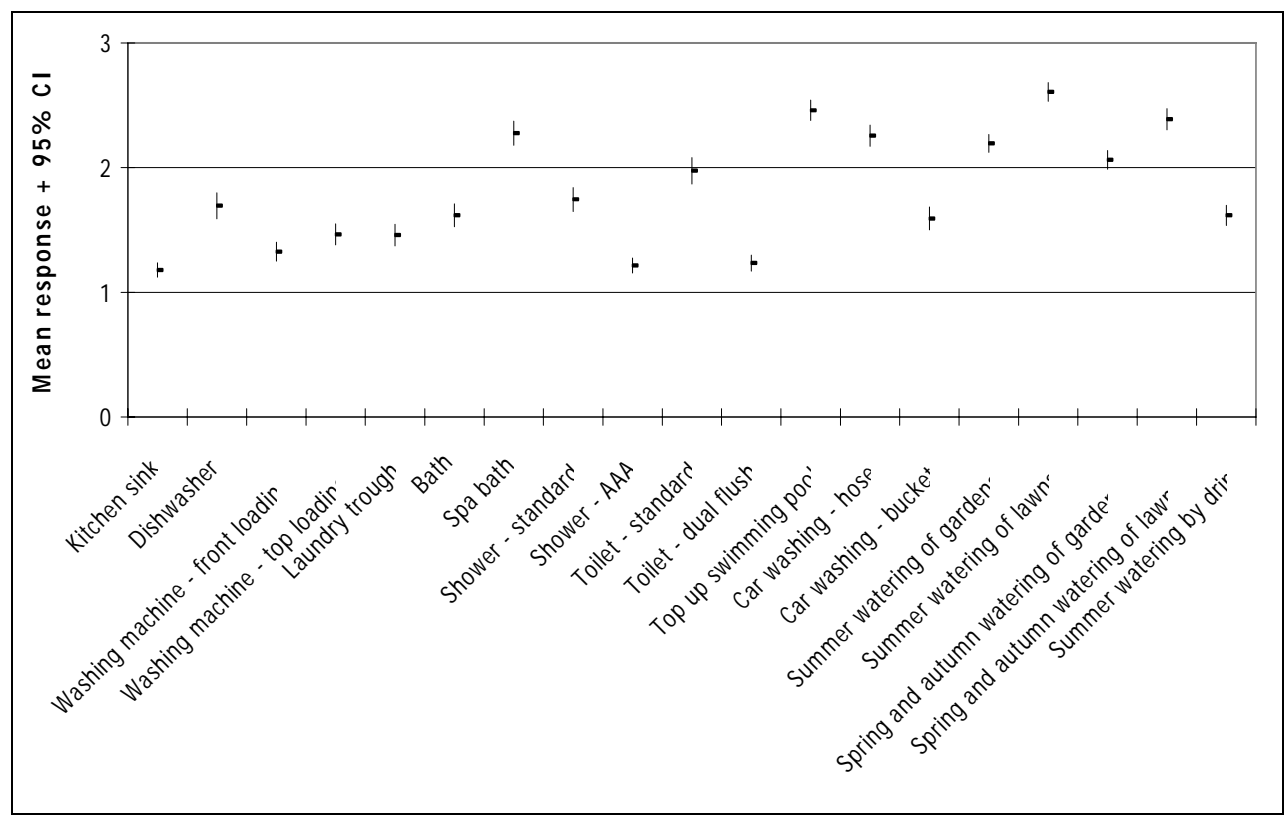

To transform these rankings into a volumetric measure that distinguished the threshold or step in the IBT, the water use attracted by each activity (as described to the respondents) was then apportioned to those activities regarded as nondiscretionary. However, this was complicated by two matters.

First, a choice needed to be made about the appropriate statistical treatment of the count data. Figure 4 has ranked each activity on the basis of their mean scores but it is also feasible to use the mode or median to generate similar rankings. Prima facie, this might seem to make little difference but, as we will see, variations can arise from this relatively simple decision. Second, an appropriate cut-off needed to be ascribed on the scale of activities. The structure of the data collected in this case makes this task less onerous. More specifically, since categories 2 and 3 were described as 'permissible with restrictions' (that is, paying a higher price) and 'heavily restricted' respectively, it has been assumed that any activity falling into these categories constitutes discretionary water use. 


\section{Figure 4: Ranking of Mean Values Assigned to Water-using Activities.}

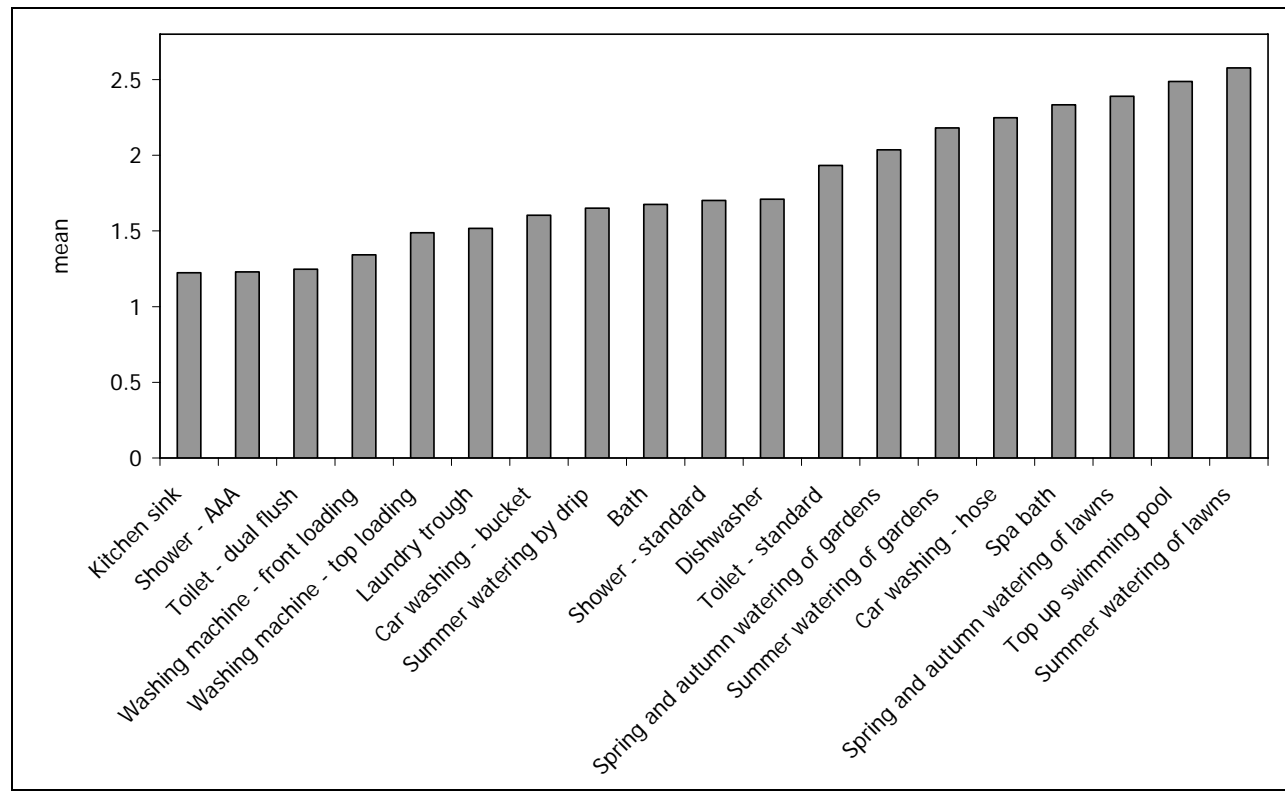

Mean, median and mode values for each activity were calculated and then each was assigned to discretionary or non-discretionary groupings. Subsequently, those activities classified as non-discretionary were allocated their notional water use, in line with the information provided to respondents. For example, using the kitchen sink generated a mean score of about 1.2 and was thus considered nondiscretionary. The quantum of water that attends this activity was $12 \mathrm{kl} /$ year and, accordingly, this quantum was assumed to lie in the first block of the IBT. This process continued for all activities and the total volume of water summed to give the non-discretionary threshold. Results are summarised in Table 2.

Table 2: Estimates of Annual Non-discretionary Volume-using Mean, Median and Mode Values Assigned to Activities

\begin{tabular}{|c|c|c|}
\hline Mean & Median & Mode \\
\hline $161 \mathrm{kl}$ & $169 \mathrm{kl}$ & $188 \mathrm{kl}$ \\
\hline
\end{tabular}

The variation in estimates occurs because more activities lie above the cut-off value when the mode and median are used to generate results compared to the mean. For instance, in Figure 2 the count data for the use of a laundry trough was provided. The mean score generated from these data was higher than that of the mode and median score - so much so that it results in this activity being classified as discretionary in one case (the mean) and non-discretionary under the mode and median estimates. 


\section{Policy I mplications and I mpacts on Customers}

Several important observations can be drawn from these data. Perhaps most striking is the relatively low threshold volume which represents the first step in any IBT that would genuinely seek to distinguish discretionary water use in the study area. Moreover, the volume generated by this process falls well short of that used in the IBTs applied in Melbourne and other parts of Victoria (commonly around $400 \mathrm{kl}$ per year). This discrepancy can be attributed to several factors. First, the relatively arbitrary nature of past decisions by regulators could account for the discrepancy. Put simply, regulators who have made choices based on discretionary and non-discretionary water-use distinctions elsewhere may have given only limited consideration to the water-using activities and their cognition by consumers. To the knowledge of the authors no regulatory agency in Australia has yet developed and prescribed a method for adjudging the volumes that should be attributed to different blocks in an IBT.

Second, consumers in different regions of Victoria could have vastly different interpretations of the status of water-related activities. Arguably, those located in rural and regional Australia may view water scarcity differently and be willing to forego more activities than their metropolitan cousins. Given the size of the discrepancy revealed by these data, this seems likely to account for only part of the divergence, at best. Adjusting these data to classify only those activities lying in the upper band as discretionary (that is, including only those ranked as heavily restricted or banned) would be one way of addressing this discrepancy. However, doing so would belie the information provided to respondents and the message embedded in the data themselves. Excessive manipulation of these data also runs the risk of imposing the same forms of arbitrary decisions that appear to have accompanied earlier IBT designs.

Third, the list of activities used in assembling these data might be regarded as incomplete and inconsistent. For instance, respondents to the survey were asked to categorise both dual flush and standard toilets, and front-loading and top-loading washing machines. These requests might be considered implausible since few households might be expected to have both types of appliances. However, the purpose of the ranking exercise was to have consumers assign their values to water-using activities and thereby differentiate between those perceived to be acceptable and essential from those perceived to be luxurious and warranting a penalty. Consequently, including a range of appliances is consistent with this approach and, in any case, is likely to inflate the estimate of nondiscretionary water use. Accordingly, this fails to adequately explain the variation between the estimates generated by these processes and those determined by the ESC.

Fourth, the discrepancies between the volumetric step assigned in Melbourne and that suggested here could be accounted for by the current political sensitivity of urban water pricing and concerns about the fairness of an IBT with a very low volume assigned to the lowest block. We have already noted that decisions about the size of each block tend to be made on political grounds. Moreover, it was the decision of economic regulators to engage in this field which prompted some of this inquiry. However, assigning a high volume to the block-one tariff to gain 
political acceptability would appear to be at odds with the justification offered for the introduction of IBTs in the first instance - namely, that they discourage and punish those who use water 'wastefully'. If discretionary water use actually commences at a much lower volume than $400 \mathrm{kl}$ per year, as suggested by these data, the structure of existing IBTs should be significantly modified to meet with this objective.

From the perspective of customers, if the water utility was to implement an IBT based on these data it would result in only a modest volume being available at the lowest marginal rate. Currently, the average household in the study area consumes about $350 \mathrm{kl}$ of water per year, well in excess of the thresholds generated by this study. Moreover, setting the threshold volume at the point suggested by these data would potentially add considerable complexity to water tariffs. A household endeavouring to determine the consequences of a change in water consumption is already confronted with non-trivial technical and practical challenges. Where the tariff structure embodies an IBT, an estimate is required to adjudge whether the proposed consumption is likely to be above or below the IBT threshold. The difficulty of this task is exaggerated by the retrospective nature of billing systems and metering devices which are often not easily accessible. Moreover, by positioning the IBT 'step' at roughly half of average consumption a large number of water users will be faced with this dilemma. Put simply, most urban water tariffs are already sufficiently complex to weaken price signals and adding an IBT 'step' at of this type seems unlikely to make this signal any clearer.

\section{Concluding Remarks}

IBTs have been widely applied by Australian urban water authorities and accepted by economic regulators as an appropriate tariff structure. Amongst their purported strengths is the capacity to design the blocks to target and discourage 'wasteful' water use by households. However, there is considerable inconsistency in tariff design across and within jurisdictions, suggesting that some states are more 'wasteful' than others or that the distinction between non-discretionary and discretionary water use has been arbitrary.

In an effort to provide a more robust mechanism for assigning the threshold volume to the first block of an IBT, primary data was collected from urban water consumers in North East Victoria. These data provided a means of categorising various water-related activities into discretionary and non-discretionary uses. By then assigning the likely water use associated with each activity, it was possible to predict the volume of water at which the second block in the IBT should commence, if the genuine objective is to limit discretionary use. Some variations in this volume emanated from the treatment of the data, but clearly the suggested volume falls well short of that which is presently applied in other IBT designs in this state.

This exercise highlights the problematic nature of IBT design and also underscores many of the theoretical objections that have been raised against IBTs generally. Moreover, IBTs result in complex tariff structures which violate efficiency and equity principles. This may well explain why economic regulators have struggled to provide comprehensive and consistent guidelines for their introduction. In this context, Boland and Whittington (2000:8) observe that 'with 
a typical IBT, it is impossible for all but the most analytical and determined user to deduce the average or marginal price that is actually being paid for water'. By way of contrast 'a tariff with a single volumetric price is simple, transparent, equitable, robust, easy to implement, and creates understandable and consistent price signals'. In addition, using a single volumetric charge does not exclude the possibility of other instruments to address concerns about the very poor and their access to water.

On the basis of these data and the mounting professional concern about the impact of IBTs, it may be preferable to defer the introduction of additional, inconsistent tariffs. Alterative approaches are available that send appropriate cost signals and optimise consumer responsiveness. In this context, a single volumetric charge with limited fixed charges, to address the revenue security of the utility, would appear preferable. Coupled with consideration of welfare measures to protect the needy, these stand to deliver enhanced efficiency and equity than that afforded by an IBT.

\section{References}

Australian Bureau of Statistics (2004), Water Account Australia 2000-01, ABS, Canberra.

Boland, J. and D. Whittington (2000), 'The Political Economy of Increasing Block Water Tariffs in Developing Countries', pp. 215-235 in A. Dinar (ed.), The Political Economy of Water Pricing, Oxford University Press, Oxford.

Department of Human Services (2004), Submission to the Essential Services Commission: Regulation of the Victorian Water Sector, Consultation Paper No. 1, DHS Concessions Unit, Melbourne.

Dwyer, T. (2006), 'Urban Water Policy: In Need of Economics', Agenda 13(1):3-16.

Edwards, G. (In press), 'Urban Water Management', in L. Crase (ed.) Water Policy in Australia, Resources for the Future Press, Washington.

Essential Services Commission (2005), Water Price Review, ESC, Melbourne.

Rogers, P., R. de. Silva and R. Bhatia (2002), 'Water is an Economic Good: How to use Prices to Promote Equity, Efficiency, and Sustainability', Water Policy 4:1-17.

Silby, H. (2006), 'Urban Water Pricing', Agenda 13(1):17-30.

United Nations (1993), Agenda 21: The UN Programme of Action from Rio, UN, New York.

Whittington, D. (2003), 'Municipal Water Pricing and Tariff Design: A Reform Agenda for South Asia', Water Policy 5:61-76.

World Health Organisation (1997), Health and Environment in Sustainable Development: Five Years after the Earth Summit, Geneva.

The authors gratefully acknowledge the financial assistance provided by the Consumer Utilities Advocacy Centre. The structure of the article has been improved by the helpful advice of two anonymous reviewers. All errors and omissions remain the responsibility of the authors. 